\title{
Cobalt (III) Oxyhydroxide as a Pyrrole Polymerization Initiator: a Theoretical Study
}

Volodymyr V. Tkach ${ }^{1,2} \mathbb{D}^{\mathbb{D}}$, Marta V. Kushnir ${ }^{1(\mathbb{D})}$, Sílvio C. de Oliveira ${ }^{2}{ }^{(\mathbb{D}}$, Yana G. Ivanushko ${ }^{3(\mathbb{D})}$, Viktoria O. Tkach 4(D), Hanna Ya. Mytrofanova ${ }^{4}\left(\mathbb{D}\right.$, Anatolii O. Zadoia ${ }^{4}$, Petro I. Yagodynets ${ }^{1(\mathbb{D})}$, Zholt O. Kormosh ${ }^{5(\mathbb{D})}$, Olga V. Luganska ${ }^{6}$ (i)

1 Chernivtsi National University, 58000, Kotsyubyns'ky Str. 2, Chernivtsi, Ukraine;nightwatcher2401@gmail.com (V.V.T.), ved1988mid@rambler.ru (P.I.Y.), marta.v.kushnir@gmail.com (M.V.K.);

2 Universidade Federal de Mato Grosso do Sul, Av. Sen. Felinto. Müller, 1555, C/P. 549, 79074-460, Campo Grande, MS, Brazil;scolive@gmail.com (S.C.O.);

3 Bukovinian State Medical University, 58001, Teatralna Sq., 9, Chernivtsi Ukraine

4 Alfred Nobel University, 49000, Naberezhna Sicheslavska Str., 18, Dnipro, Ukraine;yana_iv@ukr.net (H.Y.M.), vitt@ukr.net (V.O.T.),gglukha@duan.edu.ua (H.Y.M.), azadoia@duan.edu.ua (A.O.Z.);

5 Eastern European National University, 43000, Voli Ave., 13, Lutsk, Ukraine;zholt-1971@ukr.netkormosh@eenu.edu.ua (Z.O.K.);

6 Zaporizhzhia National University, 69600, Zhukovsky Str. 66, Zaporizhzhia, Ukraine, 130805olga@ gmail.com (O.V.L.);

* Correspondence: nightwatcher2401@ gmail.com (V.V.T.);

Received: 13.05.2021; Revised: 15.07.2021; Accepted: 18.07.2021; Published: 6.09.2021

Abstract: In this work, the possibility of using cobalt (III) oxyhydroxide as an electropolymerization initiator for pyrrole is studied by theoretical means. A hybrid material may be yielded by this synthesis. The mathematical model has been developed and analyzed using linear stability theory and bifurcation analysis: the steady-state stability requisites, correspondent to the synthesis efficiency, were obtained. The general causes for oscillatory and monotonic instabilities have also been detected.

Keywords: hybrid materials; polypyrrole; cobalt(III)oxyhydroxide; electrosynthesis; stable steadystate.

(c) 2021 by the authors. This article is an open-access article distributed under the terms and conditions of the Creative Commons Attribution (CC BY) license (https://creativecommons.org/licenses/by/4.0/).

\section{Introduction}

The conducting polymers $(\mathrm{CP})$ or, better saying, intrinsically conducting polymers compose one of the most studied classes of materials in the XXI century [1-10], due to their capacity of combining the properties of plastics with metal conductivity and facility in modification. It gives them vast and rich use in:

- corrosion protecting coatings;

- capacitors and supercapacitors;

- matrices and nanoparticle stabilizers (including the matrices for hybrid materials);

- electrode modifiers in sensors and biosensors (in which the polymer coatings may play the role of active substances and(or) mediators).

The conducting polymers may be obtained either chemically or electrochemically [1115]. Among the electrode modifying materials for assisted electropolymerization, cobalt (III) oxyhydroxide may be used. Some researchers see it as a semiconducting material as a substitute for titanium dioxide [16-20] in optical and electrochemical apparel. Its electrocatalytical and 
electroanalytical activities have already been experimentally observed $[19,20]$ and theoretically predicted [21-23].

Nevertheless, the development of new electrosynthetical processes, especially with the indirectly induced electrooxidation includes the resolution of problems like:

- Doubts in the reaction mechanism suggestions and concerning the role of the substances taking part in the process;

- The possibility of the electrochemical instabilities, characteristic either for cobalt(III) oxyhydroxideelectro-synthesis [24, 25] or for direct electropolymerization process [26-32].

Both problems may not be resolved without developing a mathematical model capable of describing the processes adequately in this system.

Therefore, the general aim of this work is the mechanistic evaluation of the possibility of pyrrole electropolymerization, assisted by $\mathrm{CoO}(\mathrm{OH})$, with the formation of their composite. It requires the satisfaction of specific objectives like:

- Suggest the reaction mechanism, including the participation of cobalt (III) oxyhydroxide in the chain initiation;

- Develop the mathematical model for this mechanism;

- Analyze the steady-state stability requirements and oscillatory and monotonic instabilities conditions using the analysis of this model;

- Compare the behavior of this system with that of analogous ones [33-35].

\section{Materials and Methods}

\subsection{System and its Modeling.}

The electropolymerization of a heterocyclic conjugated monomer may be assisted by $\mathrm{CoO}(\mathrm{OH})$ as an oxidant. In this case, for pyrrole, the reaction will be described as:

$(2 \mathrm{n}-2) \mathrm{CoO}(\mathrm{OH})+\mathrm{n} \mathrm{C}_{4} \mathrm{H}_{4} \mathrm{NH} \rightarrow \mathrm{C}_{4} \mathrm{H}_{3} \mathrm{NH}-\left(\mathrm{C}_{4} \mathrm{H}_{2} \mathrm{NH}\right)_{\mathrm{n}-2}-\mathrm{C}_{4} \mathrm{H}_{3} \mathrm{NH}+(2 \mathrm{n}-2) \mathrm{CoO}+(\mathrm{n}-1) \mathrm{H}_{2} \mathrm{O}$ (1) The regeneration of the oxyhydroxide is thus given as:

$$
\mathrm{CoO}+\mathrm{OH}^{-}-\mathrm{e}^{-} \rightarrow \mathrm{CoO}(\mathrm{OH})
$$

For the simplest case of potentiostat assisted composite electrodeposition, the process will be described by a bivariant equation set with the variables:

$\mathrm{c}$ - monomer concentration in the pre-surface layer;

$\theta$ - cobalt oxide anode coverage degree.

To simplify the modeling, we suppose that the reaction mixture is intensively stirred (so we may neglect the convection flow). Also, we simplify that the background electrolyte is in excess (so we can neglect the migration flow). Also, we suppose that the concentration profile of the substance is linear and its thickness to be constant, equal to $\delta$. At its turn, cobalt (III) oxyhydroxide is supposed to cover the entire electrode surface at the beginning of the reaction.

It is possible to show that the system's behavior, in this case, will be described by a bivariant equation set as:

$$
\left\{\begin{array}{c}
\frac{d c}{d t}=\frac{2}{\delta}\left(\frac{\Delta}{\delta}\left(c_{0}-c\right)-r_{p}\right) \\
\frac{d \theta}{d t}=\frac{1}{G}\left(r_{p}-r_{o}\right)
\end{array}\right.
$$

Where $\mathrm{c}_{0}$ is the bulk monomer concentration, $\Delta$ is the diffusion coefficient, $\mathrm{G}$ the $\mathrm{CoO}$ maximal surface concentration, and $r_{p}$ and $r_{o}$ are electropolymerization and electrooxidation rates, described as: 


$$
\begin{gathered}
r_{p}=k_{p} c^{n}(1-\theta)^{2 n-2} \\
r_{o}=k_{o} \theta \exp \frac{F \varphi_{0}}{R T}
\end{gathered}
$$

Where $\mathrm{k}$ is correspondent reaction constants, $\mathrm{n}$ is the number of monomer chains in the polymer, $\mathrm{F}$ is the Faraday number, $\varphi_{0}$ is the potential slope, related to the zero-charge potential, $\mathrm{R}$ is the universal gas constant, $\mathrm{T}$ is the absolute temperature of the solution.

This work describes the simplest case of indirect $\mathrm{CoO}(\mathrm{OH})$-assisted electropolymerization. Its differences indirect polymerization will be described below.

\section{Results and Discussion}

To describe the $\mathrm{CoO}(\mathrm{OH})$-assisted polymerization of a conjugated monomer with the example of pyrrole, we analyze the differential equation set(1) using linear stability theory. The Jacobian matrix steady-states element values may be thereby calculated as:

$\left(\begin{array}{ll}a_{11} & a_{12} \\ a_{21} & a_{22}\end{array}\right)$

in which:

$a_{11}=\frac{2}{\delta}\left(-\frac{\Delta}{\delta}-n k_{p} c^{n-1}(1-\theta)^{2 n-2}\right)$

$a_{12}=\frac{2}{\delta}\left((2 n-2) n k_{p} c^{n}(1-\theta)^{2 n-3}\right)$

$a_{21}=\frac{1}{G}\left(n k_{p} c^{n-1}(1-\theta)^{2 n-2}\right)$

$a_{22}=\frac{1}{G}\left((2 n-2) n k_{p} c^{n}(1-\theta)^{2 n-3}-k_{o} \exp \frac{F \varphi_{0}}{R T}-\xi k_{o} \theta \exp \frac{F \varphi_{0}}{R T}\right)$

Avoiding the cumbersome expressions during the Jacobian determinant analysis, we introduce new variables so that the determinant will be rewritten as:

$\frac{2}{\delta G}\left|\begin{array}{cc}-\kappa_{1}-\Xi & \Omega \\ \Xi & -\Omega-\Lambda\end{array}\right|$ 1.

The general singular point conditions for the bivariant systems may be joined in Table

Table 1. The main singular point conditions for the bivariant systems.

\begin{tabular}{l|c} 
Stable steady-state & $\operatorname{Tr} \mathrm{J}<0$, Det $\mathrm{J}>0$ \\
\hline Oscillatory behavior & $\operatorname{Tr} \mathrm{J}=0$, Det $\mathrm{J}>0$ \\
\hline Monotonic instability & $\operatorname{Tr} \mathrm{J}<0$, Det $\mathrm{J}=0$
\end{tabular}

It is possible to show that the oscillatory behavior in this system may be possible. Nevertheless, contrarily to the direct electropolymerization, it may be caused by a unique factor of the influences of the electrochemical process on the double electric layer capacities (DEL). The Hopf bifurcation condition may be realized only by the positivity of the parameter $\xi$, describing the mentioned influences. The oscillations are expected to be more frequent and have smaller amplitude than during the direct electropolymerization [29-32]. Mathematically, the condition of the oscillatory behavior may be described as (10):

$$
\left\{\begin{array}{c}
\frac{2}{\delta}\left(-\kappa_{1}-\Xi\right)=\frac{1}{G}(\Lambda+\Omega) \\
\kappa_{1} \Omega+\kappa_{1} \Lambda+\Xi \Lambda>0
\end{array}\right.
$$

To investigate the steady-state stability, we apply the condition $\operatorname{Tr} \mathrm{J}<0$, Det $\mathrm{J}>0$ (see the table). As shown, in the case of the relative fragility of the electrochemical stage on DEL capacitances, described by the positivity of $\Lambda$, condition (1) is warranted to be satisfied. If $\Lambda>0,-\kappa_{1}-\Xi-\Omega-\Lambda<0$, due to the positivity of other parameters forming the equation. Also, $\kappa_{1} \Omega+\kappa_{1} \Lambda+\Xi \Lambda>0$, if $\Lambda>0$, also taking into account the factors mentioned above. Thus, it is possible to conclude about the electrosynthetical efficiency of this system, as the 
steady-state stability is easy to obtain and maintain and, due to the absence of the side reactions, capable of compromise the electropolymerization, modifier, and monomer stability.

Moreover, taking into account the mentioned factors, the steady-state topological zone will be wider than during the direct electropolymerization, as there are fewer factors capable of destabilizing the steady-state [33-35]. Depending in the monomer concentration and on the electrode shape, the system may be diffusion and reaction-controlled.

Monotonic instability is manifested by an N-shaped part of the voltammogram. It is also caused by DEL influences on the electrochemical reaction. Its condition may be described as:

$$
\left\{\begin{array}{c}
-\frac{2}{\delta}\left(\kappa_{1}+\Xi\right)-\frac{1}{G}(\Lambda+\Omega)<0 \\
\kappa_{1} \Omega=-\kappa_{1} \Lambda-\Xi \Lambda
\end{array}\right.
$$

It may be satisfied only with negative values of $\Lambda$ and separates the steady, stable states from unstable states.

In the case of polymerization in the presence of complex-forming ions, the complex formation may dissolve the trivalent cobalt in a complex, so these processes may concur. This case will be aborded in our next works.

If the polymerization potential of the monomer is relatively high (as in the case of thiophene), the $\mathrm{CoO}(\mathrm{OH}) / \mathrm{CoO}_{2}$ may be used. Two scenarios are possible for this case - with and without the chemically induced polymer overoxidation. In the simplest case, the present model may be applied (with some rectification). For the second case, the trivariate mathematical model describing it will be described in our next works.

\section{Conclusions}

From the theoretical description of the anodic conducting polymer assisted electrodeposition catalyzed by $\mathrm{CoO}(\mathrm{OH})$, it is possible to conclude that from the electrosynthetical point of view, this process has to be more efficient than the direct electropolymerization due to the better probability of stable steady-state. The oscillatory instability, in this case, is possible, but it is less probable than in the case of direct electropolymerization, being caused uniquely by electrochemical factors. Depending on the monomer concentration and electrode shape, the electrosynthesis may be diffusion and kinetically controlled.

\section{Funding}

This research received no external funding.

\section{Acknowledgments}

This research has no acknowledgment.

\section{Conflicts of Interest}

The authors declare no conflict of interest.

\section{References}

1. Liu, X.; Liu, J. Biosensors and Sensors for Dopamine Detection. View 2021, 2, https://doi.org/10.1002/VIW.20200102. 
2. Karthika, A.; Ramasamy Raja, V.; Karuppasamy, P.; Suganthi, A.; Rajarajan, M. A novel electrochemical sensor for determination of hydroquinone in water using FeWO4/SnO2 nanocomposite immobilized modified glassy carbon electrode. Arabian Journal of Chemistry 2020, 13, 4065-4081, https://doi.org/10.1016/j.arabjc.2019.06.008.

3. Kumar, Y.; Vashistha, V.K.; Das, D.K. Synthesis of Perovskite-type $\mathrm{NdFeO}_{3}$ nanoparticles and used as electrochemical sensor for detection of paracetamol. Lett. Appl. Nanobiosci. 2020, 9, 866-869, https://doi.org/10.33263/LIANBS91.866869.

4. Sá, A.C.D.; Barbosa, S.C.; Raymundo-Pereira, P.A.; Wilson, D.; Shimizu, F.M.; Raposo, M.; Oliveira, O.N. Flexible Carbon Electrodes for Electrochemical Detection of Bisphenol-A, Hydroquinone and Catechol in Water Samples. Chemosensors 2020, 8, https://doi.org/10.3390/chemosensors8040103.

5. Koçak, Ç.C.; Koçak, S. Enhanced Electrochemical Determination of Catechol and Hydroquinone Based on Pd Nanoparticles/Poly(Taurine) Modified Glassy Carbon Electrode. Electroanalysis 2020, 32, 358-366, https://doi.org/10.1002/elan.201900500.

6. Joshi, N.C.; Malik, S.; Gururani, P. Utilization of Polypyrrole/ZnO Nanocomposite in the Adsorptive Removal of $\mathrm{Cu} 2+, \mathrm{Pb} 2+$ and $\mathrm{Cd} 2+$ Ions from Wastewater. Letters in Applied NanoBioScience 2021, 10, 2339-2351, https://doi.org/10.33263/LIANBS103.23392351.

7. Nowicki, G.J.; Ślusarska, B.; Prystupa, A.; Blicharska, E.; Adamczuk, A.; Czernecki, T.; Jankowski, K.J. Assessment of Concentrations of Heavy Metals in Postmyocardial Infarction Patients and Patients Free from Cardiovascular Event. Cardiology Research and Practice 2021, 2021, https://doi.org/10.1155/2021/9546358.

8. Tnoumi, A.; Angelone, M.; Armiento, G.; Caprioli, R.; Crovato, C.; De Cassan, M.; Montereali, M.R.; Nardi, E.; Parrella, L.; Proposito, M.; Spaziani, F.; Zourarah, B. Assessment of Trace Metals in Sediments from Khnifiss Lagoon (Tarfaya, Morocco). Earth 2021, 2, 16-31, https://doi.org/10.3390/earth2010002.

9. Li, S.; Sun, X.; Li, S.; Liu, Y.; Ma, Q.; Zhou, W. Effects of amendments on the bioavailability, transformation and accumulation of heavy metals by pakchoi cabbage in a multi-element contaminated soil. RSC Advances 2021, 11, 4395-4405, https://doi.org/10.1039/D0RA09358K.

10. Stejskal, J.; Kohl, M.; Trchová, M.; Kolská, Z.; Pekárek, M.; Křivka, I.; Prokeš, J. Conversion of conducting polypyrrole nanostructures to nitrogen-containing carbons and its impact on the adsorption of organic dye. Materials Advances 2021, 2, 706-717, https://doi.org/10.1039/D0MA00730G.

11. Gu, Y.; Qiao, Y.; Meng, Y.; Yu, M.; Zhang, B.; Li, J. One-step synthesis of well-dispersed polypyrrole copolymers under gamma-ray irradiation. Polymer Chemistry 2021, 12, 645-649, https://doi.org/10.1039/D0PY01566K.

12. Kaynak, A.; Zolfagharian, A.; Featherby, T.; Bodaghi, M.; Mahmud, M.A.P.; Kouzani, A.Z. Electrothermal Modeling and Analysis of Polypyrrole-Coated Wearable E-Textiles. Materials 2021, 14, https://doi.org/10.3390/ma14030550.

13. Zarei, M.; Samimi, A.; Khorram, M.; Abdi, M.M.; Golestaneh, S.I. Fabrication and characterization of conductive polypyrrole/chitosan/collagen electrospun nanofiber scaffold for tissue engineering application. International Journal of Biological Macromolecules 2021, 168, 175-186, https://doi.org/10.1016/j.ijbiomac.2020.12.031.

14. Wang, Z.; Zou, Y.; Li, Y.; Cheng, Y. Metal-Containing Polydopamine Nanomaterials: Catalysis, Energy, and Theranostics. Small 2020, 16, https://doi.org/10.1002/smll.201907042.

15. Jin, A.; Wang, Y.; Lin, K.; Jiang, L. Nanoparticles modified by polydopamine: Working as "drug" carriers. Bioactive Materials 2020, 5, 522-541, https://doi.org/10.1016/j.bioactmat.2020.04.003.

16. Mashhadizadeh, M.H.; Kalantarian, S.M.; Azhdeh, A. A Novel Electrochemical Sensor for Simultaneous Determination of Hydroquinone, Catechol and Resorcinol Using a Carbon Paste Electrode, Modified by ZnMOF, Nitrogen-Doped Graphite and AuNPs. Electroanalysis 2020, 32, https://doi.org/10.1002/elan.202060326

17. Rajaram, R.; Kiruba, M.; Suresh, C.; Mathiyarasu, J.; Kumaran, S.; Kumaresan, R. Amperometric determination of Myo-inositol using a glassy carbon electrode modified with nanostructured copper sulfide. Microchimica Acta 2020, 187, https://doi.org/10.1007/s00604-020-04300-z.

18. Al-Shar'i, N.A.; Al-Balas, Q.A.; Hassan, M.A.; El-Elimat, T.M.; Aljabal, G.A.; Almaaytah, A.M. Ellagic acid: A potent glyoxalase-I inhibitor with a unique scaffold. Acta pharmaceutica (Zagreb, Croatia) 2021, 71, 115-130, https://doi.org/10.2478/acph-2021-0005.

19. Hering, N.A.; Luettig, J.; Jebautzke, B.; Schulzke, J.D.; Rosenthal, R. The Punicalagin Metabolites Ellagic Acid and Urolithin A Exert Different Strengthening and Anti-Inflammatory Effects on Tight JunctionMediated Intestinal Barrier Function In Vitro. 2021, 12, https://doi.org/10.3389/fphar.2021.610164.

20. Li, Y.; Mei, L.; Guan, X.; Hu, Y. Ellagic acid solid dispersion: Characterization and bioactivity in the hydroxyl radical oxidation system. Food Research International 2021, 142, https://doi.org/10.1016/j.foodres.2021.110184.

21. Melgarejo-Sánchez, P.; Núñez-Gómez, D.; Martínez-Nicolás, J.J.; Hernández, F.; Legua, P.; Melgarejo, P. Pomegranate variety and pomegranate plant part, relevance from bioactive point of view: a review. Bioresources and Bioprocessing 2021, 8,https://doi.org/10.1186/s40643-020-00351-5. 
22. Moga, M.A.; Dimienescu, O.G.; Bălan, A.; Dima, L.; Toma, S.I.; Bîgiu, N.F.; Blidaru, A. Pharmacological and Therapeutic Properties of Punica granatum Phytochemicals: Possible Roles in Breast Cancer. Molecules 2021, 26, https://doi.org/10.3390/molecules26041054.

23. Ziyatdinova, G.; Guss, E.; Morozova, E.; Budnikov, H.; Davletshin, R.; Vorobev, V.; Osin, Y. Simultaneous voltammetric determination of gallic and ellagic acids in cognac and brandy using electrode modified with functionalized SWNT and poly(pyrocatechol violet). Food Analytical Methods 2019, 12, 2250-2261, https://doi.org/10.1007/s12161-019-01585-6.

24. Sabbaghi, N.; Noroozifar, M.; Kerman, K. Nanocomposite of Ellagic Acid with Multi-Walled Carbon Nanotubes for the Simultaneous Voltammetric Detection of Six Biomolecules. Feature Papers in the Science and Engineering of Carbons2021, 7, https://doi.org/10.3390/c7020043.

25. Manjunatha, J. Poly(Adenine) Modified Graphene-Based Voltammetric Sensor for the Electrochemical Determination of Catechol, Hydroquinone and Resorcinol. The Open Chemical Engineering Journal 2020, 14, 52-62, https://doi.org/10.2174/1874123102014010052.

26. Ahmad, K.; Kumar, P.; Mobin, S.M. A highly sensitive and selective hydroquinone sensor based on a newly designed N-rGO/SrZrO3 composite. Nanoscale Advances 2020, 2, 502511,https://doi.org/10.1039/c9na00573k.

27. Romero-Montero, A.; del Valle, L.J.; Puiggalí, J.; Montiel, C.; García-Arrazola, R.; Gimeno, M. Poly(gallic acid)-coated polycaprolactone inhibits oxidative stress in epithelial cells. Materials Science and Engineering: C 2020, 115, https://doi.org/10.1016/j.msec.2020.111154.

28. Zamudio-Cuevas, Y.; Andonegui-Elguera, M.A.; Aparicio-Juárez, A.; Aguillón-Solís, E.; Martínez-Flores, K.; Ruvalcaba-Paredes, E.; Velasquillo-Martínez, C.; Ibarra, C.; Martínez-López, V.; Gutiérrez, M.; GarcíaArrazola, R.; Hernández-Valencia, C.G.; Romero-Montero, A.; Hernández-Valdepeña, M.A.; Gimeno, M.; Sánchez-Sánchez, R. The enzymatic poly(gallic acid) reduces pro-inflammatory cytokines in vitro, a potential application in inflammatory diseases. Inflammation 2021, 44, 174-185, https://doi.org/10.1007/s10753-02001319-5.

29. Yang, P.; Zhang, S.; Chen, X.; Liu, X.; Wang, Z.; Li, Y. Recent developments in polydopamine fluorescent nanomaterials. Materials Horizons 2020, 7, 746-761, https://doi.org/10.1039/c9mh01197h.

30. Das, I.; Goel, N.; Agrawal, N.R.; Gupta, S.K. Growth patterns of dendrimers and electric potential oscillations during electropolymerization of pyrrole using mono-and mixed surfactants. J. Phys. Chem. B 2010, 114, 12888-12896, https://doi.org/10.1021/jp105183q.

31. Das, I.; Goel, N.; Gupta, S.K.; Agrawal, N.R. Electropolymerization of pyrrole: Dendrimers, nano-sized patterns and oscillations in potential in presence of aromatic and aliphatic surfactants. J. Electroanal. Chem.2012, 670, 1-10, https://doi.org/10.1016/j.jelechem.2012.01.023.

32. Tkach, V.V.; Kushnir, M.V.; Ivanushko, Y.G.; de Oliviera, S. The Theoretical Description for Neotame Electrochemical Determination, Assisted by Vanadium Oxyhydroxide Composite with a Squarainic Dye. Appl. J. Env. Eng. Sci. 2020, 6, 109-115.

33. Tkach, V.V.; Kushnir, M.V.; Storoshchuk, N.M.; Ivanushko, Y. The Theoretical Description for the Confection of the Novel Thiourea-Based Active Surface for Cathodic Conducting Polymer Deposition. Appl. J. Env. Eng. Sci.2020, 6, 143-148.

34. Tkach, V.; Kushnir, M.; Ivanushko, Y.; de Oliveira, S.; Reis, L.; Yagodynets`, P.; Kormosh, Z. The Theoretical Description for the Electrochemical Synthesis of Squaraine Dye Doped Conducting Polymer. Appl. J. Env. Eng. Sci. 2020, 6, 51-56.

35. Tkach, V.V.; Storoshchuk, N.M.; Romaniv, L.V.; De Oliveira, S.C.; Luganska, O.V.; Gala, H.B.; Tchikuala, E.F.; Yagodynets, P.I. The theoretical evaluation of the poly(3,4-dimetylpyrrole) cathodic electrodeposition assisted by manganate ions. Vietnam Journal of Chemistry 2018, 56, 440-444, https://doi.org/10.1002/vjch.201800027. 